\title{
INSTRUMENTOS DE PESQUISA PARA A HISTÓRIA DE SÃO PAULO
}

\author{
Raquel Glezer \\ Depto. de História, FFLCH da USP.
}

Nos últimos dois anos historiadores e pesquisadores da história da cidade de São Paulo foram surpreendidos com a publicação de vários instrumentos de pesquisa, na perspectiva da pesquisa pública, que socializando informações sobre arquivos existentes, acervos documentais textuais e iconográficos, relacionando teses e dissertações (em sua maioria não editada) ou indicando os "sebos" existentes, prestam serviço inestimável e contribuem para o crescimento dos campos especializados.

Muitas dessas informações, recentemente publicadas, eram dados esparsos, conhecidos, mas individuais, memória de pesquisadores, resultado de trajetórias e trabalhos, experiências de pesquisa isoladas, relembradas quando algum pesquisador iniciante busca informações com outro mais antigo.

Característica comum de várias delas é o fato de serem resultantes de projetos de pesquisa estruturados como projetos institucionais, com apoio financeiro, quer de agência financiadora nacional ou estadual, quer através de incentivos culturais, com perfil de formação de pesquisadores, demonstração dos resultados da política de formação de recursos humanos na área de História no Brasil e especialmente na da história de São Paulo.

Destacamos que a coincidência de os lançamentos se concentrarem em curto espaço de tempo faz com que se apresentem como a retomada de uma tradição dos estudos históricos brasileiros, que parecia estar sendo considerada menor, relegada ao esquecimento, quase o resultado inesperado e não-desejado da crítica à história denominada "metódica", "positivista" ou "tradicional". Aparentemente, a valorização de uma "Nova História" com "novos sujeitos sociais, novos objetos e novas fontes", em vez de reforçar a necessidade de aprofundamento do instrumental documental, estava deixando de lado o básico e tradicional - as ferramentas de trabalho: catálogos de acervos, guias bibliográficos, edição de fontes etc., a "Heurística" dos clássicos manuais de introdução aos estudos históricos, relegada aos "eruditos".

A existência, permanência, e constante atualização dos instrumentos de pesquisa são fundamentais para o desenvolvimento contínuo dos estudos históricos, mantendo a memória do produzido (documental textual, iconográfico e bibliográfico) e realizando a 
socialização das informações (sobre arquivos, acervos, fontes ou produção com bibliografias gerais e especializadas). O conhecimento e domínio deles são um dos elementos que separa o historiador de formação universitária dos diletantes, curiosos e jornalistas, que escrevem e publicam "história".

Apesar das dificuldades atuais existentes nas atividades de preservação documental e bibliográfica básicas, como as do Sistema Nacional de Arquivos, de alguns Sistemas Estaduais de Arquivos e do Projeto RECIS (discutido desde os anos 80, propondo a ligação eletrônica de acervos informatizados de bibliotecas no país) temos alguma tradição em organização e edição de instrumentos de pesquisa ${ }^{1}$, e é importante o retorno dessas práticas, que significam ampliação do campo de trabalho para os profissionais graduados em História, demonstrando na atividade concreta os resultados do processo de formação de novos especialistas, nos cursos de graduação e pós-graduação.

A Divisão dos Arquivos do Estado da Secretaria de Estado da Cultura de São Paulo/DAESP retomou as publicações em 1997, distribuídas em grande parte no ano seguinte, paralisadas por problemas de instalação espacial e financeiro, com o lançamento de várias obras instrumentais sobre seu acervo.

A retomada foi com o Guia do acervo (DAESP, 1997a), versão atualizada da obra editada em 1995 , comemorando a transferência e instalação do Arquivo no novo prédio ${ }^{2}$. Em formato 21 x $28 \mathrm{~cm}$., com 88

${ }^{1}$ Refiro-me as obras instrumentais gerais: Rubens Borba de Moraes \& William Berrien (ed.). Manual bibliográfico de estudos brasileiros. Rio de Janeiro: Gráfica Ed. Souza, 1949; Bibliografia de História do Brasil, 1943-1958; 1959/69. Rio de Janeiro: Comissão de Estudos dos Textos da História do Brasil/Seção de Publicações/Ministério de Relações Exteriores, 1944 a 1971, 15 v.; Nelson Werneck Sodré. O que se deve ler para conhecer o Brasil. Rio de Janeiro: INL/MEC, 1962. Depois, ficamos dependentes do Handbook of Latin American Studies, publicado desde 1936; dos guias como os de S.A. Bayitch. Latin America. A bibliographical guide to economy, history, páginas contém: Apresentação, do Dr. Fausto Couto Sobrinho, Diretor do Arquivo; Histórico da instituição; O Arquivo Permanente, subdividido em Arquivos Públicos, Arquivo Privados e Documentação Iconográfica; O Arquivo Intermediário; Apoio à Pesquisa, subdividido em Biblioteca, Conservação e Publicações, Galeria dos Diretores e Quadro de Funcionários. O texto é da equipe técnica do Arquivo, que atualizou os dados da anterior, incluindo os novos acervos e seções.

$\mathrm{Na}$ mesma oportunidade editou Os voluntários paulistas na Guerra do Paraguai (DAESP, 1997 b) documento que formaliza a "entrega e depósito da Bandeira do $35^{\circ}$. Corpo de Voluntários da Pátria da Província de São Paulo na Catedral da imperial Cidade de São Paulo", com documentos iconográficos e do arquivo permanente. A capa da obra reproduz a do documento, no formato $22 \times 32 \mathrm{~cm}$., contendo: Apresentação, do Dr. Fausto Couto Sobrinho, e "A Guerra do Paraguai e seu contexto histórico", de Edgard Luiz de Barros, traçando o quadro histórico do Paraguai, as razões da Guerra, a articulação da Tríplice Aliança e o começo do conflito, descrevendo os exércitos inimigos, as movimentações militares, as principais batalhas, as conseqüências da Guerra, das páginas 8 a 30. Daí em diante está a reprodução

law, politics and society. Coral Gables/Florida/USA: University of Miami Press, 1964, e, mais recentemente Ann Hartness. Brazil in Reference Books, 1965-89. New York: The Scarecrow Press, 1991.Sobre São Paulo existem: Manual Bibliográfico da Geografia Paulista (jun. 1956), org. Comissão de Geografia Regional. São Paulo: IBGE/ Conselho Nacional de Geografia, 1957, e, Evolução Urbana da Cidade de São Paulo. Estruturação de uma cidade industrial (18721945), coord. Maria Lúcia Perrone Passos. São Paulo: ELETROPAULO/Secretaria Municipal de Cultura, 1990.

${ }^{2}$ A Divisão dos Arquivos do Estado da Secretaria da Cultura do Estado está localizada na Rua Voluntários da Pátria, nº. 596, Santana, próxima à Estação Tietê do Metrô. 
documento do Voluntários Paulistas. Recepção de sua gloriosa bandeira, 1870, com transcrição, páginas 31 a 40; Voluntários paulistas (1865-1870) mapas nas páginas 41 a 64; Voluntários paulistas (1865-1890), com 26 documentos reproduzidos da 65 a 133 e transcrições, da 135 em diante.

Como parte do Convênio Arquivo do Estado/Universidade de São Paulo, que conta com apoio do CNPq e da FAPESP, foi publicado o resultado inicial do trabalho coordenado pela Profa. Dra. Maria Luiza Tucci Carneiro, Inventário DEOPS - Alemanha (DAESP, 1997 c), formato 16 x $23 \mathrm{~cm}$., contendo: Agradecimentos; Apresentação, do Dr. Fausto Couto Sobrinho; Prefácio, Dr. Dieter Strauss; Introdução, do Prof. Dr. Nilo Odalia; O Projeto Integrado Arquivo/Universidade e o acervo DEOPS; "A comunidade alemã e os mecanismos de controle social", da Profa. Dra. Maria Luiza Tucci Carneiro; Módulo I - Alemanha "O Partido Nazista em São Paulo", de Ana Maria Dietrich; "Espionagem nazista e contra-espionagem policial", de Priscila Ferreira Perazzo; "A comunidade alemã sob suspeita", de Eliane Bisan Alves; Índice de assuntos; Índice de Ilustrações, Bibliografia.

O acervo DEOPS/SP foi entregue em 1991 à guarda da Divisão de Arquivo do Estado e a consulta aos documentos está submetida a uma legislação específica.

Resultado das atividades conjuntas entre a Divisão do Arquivo do Estado e o departamento de História da Pontifícia Universidade Católica de São Paulo/PUC-SP, com apoio do CNPq, é o catálogo de periódicos publicados na cidade entre 1870 e 1930, organizado pela Profa. Dra. Heloísa de Faria Cruz, São Paulo em revista (DAESP, 1997 d), colaboração do Centro de Documentação e Informação Científica "Prof. Casemiro Reis Filho" - CEDIC/PUC-SP, com a DAESP e a Imprensa Oficial do Estado/IMESP.

O Centro de Documentação e Informação Científica "Prof. Casemiro Reis Filho" - CEDIC/PUC-SP é um centro de documentação universitário, sob direção da Profa. Dra. Yara Aun Khoury, que além das tarefas de preservação de fundos e coleções de movimentos sociais e populares, se preocupa com a carência de instrumentos de pesquisa, e colaborando com o aperfeiçoamento dos estudos históricos, atua na produção de inventários, catálogos, guias de pesquisa e/ou em publicação, na Coleção memória, documentação e pesquisa.

A origem do catálogo foi a pesquisa realizada sobre a imprensa paulistana, entre o último quartel do século XIX e primeiro do XX, para explorar as relações entre cultura letrada, periodismo e vida urbana, na fase de doutorado da organizadora. Com a orientação técnica do CEDIC na formatação da ficha técnica, participação de alunos de graduação e graduados do Departamento de História da PUC-SP, e pesquisadores do Arquivo, foram arrolados todos os títulos de periódicos encontrados em seis instituições de guarda de acervos (Arquivo do Estado, Biblioteca Mário de Andrade, BMA em Santo Amaro, Escola de Comunicações de Artes/USP, Instituto de Estudos Brasileiros/USP e Instituto Histórico e Geográfico de São Paulo), escolhidos pela importância e volume da documentação preservada.

Após uma seleção pelo conteúdo definido - publicações culturais e de variedades, deixando de lado todos os outros tipos de periódicos, foi possível delimitar a massa documental, mais de 500 títulos de revistas que circularam na cidade, o que permite captar todas as transformações que ocorreram na sociedade paulistana, com a emergência de novos atores sociais e culturais e a recuperação do quotidiano através dos assuntos do dia a dia. Apresentado em edição ilustrada, com alta qualidade gráfica, em formato $22 \mathrm{x}$ $22 \mathrm{~cm}$, contém: Apresentação, do Dr. Fausto Couto Sobrinho; Prefácio, da Profa. Dra. Yara Aun Khoury; Introdução, da Profa. Dra. Heloísa de Faria Cruz; Periódicos Paulistanos (1870-1930); Índice de Assuntos; Índice Cronológico e Instituições Citadas. O catálogo propriamente dito está no item Periódicos Paulistanos, da página 37 até a 271, em ordem alfabética e 
numerada, das fichas técnicas de A Academia de São Paulo (001) a Zuavo (523), título e subtítulo completos, características técnicas, produção e distribuição, conteúdo e acervo, com dados sobre local de depósito e os volumes existentes. Os índices de assuntos e cronológico facilitam a consulta dos pesquisadores, e permitem a visualização e percepção dos temas com produção mais volumosa e dos momentos de maior dinamismo do mercado editorial, mesmo restrito numérica e tecnologicamente.

Mesmo que o catálogo não seja total e completo, sua realização e edição representam colaboração importante para o desenvolvimento dos estudos sobre a cidade de São Paulo.

Crimes em São Paulo (DAESP, 1998 a) é o resultado de projeto e trabalho interno, desenvolvido por técnicos e estagiários, com consultoria arquivística de Heloísa Liberalli Bellotto, um projeto piloto de tratamento técnico-arquivístico aos fundos dos Juízos da Capital, com financiamento pelo Fundo Nacional de Cultura da Secretaria de Apoio à Cultura do Ministério da Cultura e apoios da Fundação para o Desenvolvimento da UNESP/FUNDUNESP e da Imprensa Oficial do Estado de São Paulo/IMESP. Além do catálogo, resultaram do projeto o Manual de procedimentos (DAESP, 1998 b), a microfilmagem do material documental e um Banco de Dados, para consulta em rede local e Internet.

O catálogo está organizado em: Apresentação, do Dr. Fausto Couto Sobrinho; Introdução, de Marco Antônio Cabral dos Santos e Patrícia Menezes; "O processo criminal durante o Império", de Patrícia Menezes, e Documentos dos Juízos da Capital, no formato 21 x $28 \mathrm{~cm}$, sem índices. O item Introdução descreve a situação existente e as formas de localização da documentação, procedimentos técnicos de conservação adotados, o arranjo documental decorrente da pesquisa sobre legislação, os grupos documentais definidos e as séries, atividades de descrição e as de produção do instrumento de pesquisa. $\mathrm{O}$ ca- pítulo "O processo criminal durante o Império", sintético, mas substancial, recupera as transformações do aparelho judicial desde o período colonial, com atenção no Reino Unido - autonomia da Justiça no Brasil, e, no Império, da Carta Outorgada de 1824 ao Código de Processo Criminal, de 1832, descentralizador, que foi reformado em 1841, com Regulamento em 1842, centralizando na Corte procedimentos processuais e operacionais. Mesmo assim, a coexistência da dupla função policial e judicial, originária das Ordenações, continuou existindo até 1871 . O catálogo ocupa as páginas de 25 a 379, subdividido em: Processos criminais; Execuções de Sentenças; Recursos e Apelações; Habeas-corpus e Termos de bem-viver.

Os dois outros catálogos, igualmente resultantes de trabalho interno, com apoio da FUNDUNESP e IMESP, são Arquivo em imagens, 1 (DAESP, 1998 c) e 2 (DAESP, 1998 d), iniciando a divulgação do Setor Iconográfico, um dos mais recentes na estrutura organizacional do Arquivo.

Arquivo em Imagens, 1 - Série Última Hora está organizado em: Apresentação, do Dr. Fausto Couto Sobrinho; Introdução, de Rosimeire dos Santos e Sílnia Nunes Martins; "O Arquivo abriga o passado e o futuro", de Augusto Nunes; "Última Hora: batalhas perdidas, vitória na guerra", de Maria Aparecida de Aquino, e "Retratos de um Jornal", no formato de $23 \times 23 \mathrm{~cm}$, sem índices.

A documentação do jornal diário Última Hora (1951-1971) foi adquirida pela Secretaria de Cultura do Estado de São Paulo em 1989 e depositada no Arquivo do Estado, dando início ao Setor Iconográfico, com mais de 160.000 fotos, organizadas na estrutura original do acervo, por assuntos.

Os artigos de Augusto Nunes e Maria Aparecida de Aquino apresentam o proprietário, Samuel Wainer, e o jornal, com seu destacado papel de inovação jornalística e participação na vida política nacional. As fotos estão editadas por assuntos e em ordem cronológica de publicação, e referentes a: Política, da pá- 
gina 27 a 65; Artes, da 67 a 100; Polícia, da 101 a 121; Geral, da 123 a 151, e, Esportes, da 151 a 176.

Arquivo em Imagens, 2 - Série Última Hora Futebol está organizado em: Apresentação, do Dr. Fausto Couto Sobrinho; Introdução, de Letícia Fagundes de Oliveira e Paulo de Tarso Amaral Penteado; "UH num tempo de fé e humor", de Alberto Helena Júnior; "A epifânia das noites de quarta e as tardes de sábado e domingo", de Walter Firmo; "Jornal Última Hora", de Flávio Prado; "Futebol”, de José Sebastião Witter; Copas do Mundo, Geral e Glossário, no formato de $23 \times 23 \mathrm{~cm}$, com Ficha Técnica no final, sem índices.

Os artigos apresentam a relação estabelecida pelo jornal com a paixão dos leitores/torcedores através de rememorações e lembranças pessoais de comentarista esportivo, fotógrafo e jornalista, e um histórico do esporte no Brasil. As fotos estão apresentadas em ordem cronológica de publicação, em Copas do Mundo, da página 35 até a 114, com Copa de 54, Copa de 58, Copa de 62, Copa de 66, Copa de 70. Em Geral, da página 115 até 173, estão as fotos de Futebol Nacional, Goleiros, Personalidades e Torcedores.

Os catálogos de material dos acervos do Arquivo do Estado, realizados por seus funcionários e estagiários, representam a retomada das atividades arquivísticas e de pesquisas, que estiveram em segundo plano, durante o período de mudança da Rua Antônia de Queiroz para a sede atual. São eles contribuições importantes para o conhecimento e divulgação do acervo histórico, mas a inexistência de índices de assunto e onomásticos dificulta o trabalho dos pesquisadores. Quanto aos catálogos de fotos, faltam os dados dos fotógrafos, que contribuiriam para o conhecimento da história da fotografia jornalística brasileira. Também a variedade de formatos não indica a identidade da depositária. Mas estes são pequenos detalhes diante do porte das tarefas empreendidas, executadas do melhor modo possível, mesmo sem a existência de condições ideais em termos de recursos materiais.
Outro instrumento de pesquisa, o Guia dos documentos históricos (FERNANDES, 1998) contou com o apoio institucional da COLGATE-PALMOLIVE e Prefeitura do Município de São Paulo, através da Lei 10.923/90 de incentivo cultural. O trabalho de pesquisa e edição foi desenvolvido pelo setor de história do Núcleo de Estudos de Política e Sociedade/NEPS, fundado em 1991 por pesquisadores das áreas de ciências humanas da Universidade de São Paulo, instituição sem fins lucrativos voltada para estudos e pesquisas da realidade brasileira. Do trabalho de 18 meses de pesquisa e edição, sob a coordenação de Paula Porta S. Fernandes participaram Márcia Padilha Lotito, Maria Cristina Cortez Wissenbach, Malu de Oliveira, Paulo César Garcez Marins, Pedro Puntoni e Sílvia Q. F. Barreto Lins, graduados em História pelo Departamento de História/FFLCH, Mestres e Doutores em História Social/FFLCH/USP.

O Guia tem por objetivo localizar, descrever e divulgar as instituições que guardam documentação existente no município, criadas até 1954, referentes à cidade e ao país, com mais de 1000 indicações de locais com acervos de documentos textuais originais: arquivos, associações, bibliotecas, centros de pesquisa, clubes, escolas, igrejas, indústrias, lojas, museus, órgãos de imprensa, restaurantes, sindicatos....

O volume está estruturado em: Apresentação, de Angel Martinez, Presidente da COLGATE-PALMOLIVE; Prefácio, de Maria Odila Leite da Silva Dias; Agradecimentos; Introdução, de Paula Porta S. Fernandes; Como utilizar o Guia; Sumário; o guia; Anexo, Índice alfabético e Índice cronológico. A capa e contracapa protetora são fotos de Cristiano Mascaro, o Viaduto do Chá e um "sky-line" da cidade, e o projeto gráfico é de Roberta Asse. Na contracapa externa há uma apresentação sintética de Aziz Ab'Saber. O formato é 17 x $26,5 \mathrm{~cm}$, na edição em capa dura.

Conforme Maria Odila Leite da Silva Dias declara em seu Prefácio, este tipo de obra é relevante pela apresentação de acervos, muitos dos quais escondi- 
dos, esquecidos, permitindo a recuperação da história administrativa, pública e social da cidade, através da diversidade de documentos e multiplicidade de discursos, abrangendo o público e o privado. A ampla conceituação de documentação textual favorece a recuperação de dados para múltiplos estudos, para a multidisciplinariedade das ciências humanas, os variados aspectos da convivência e vivência humana que transformaram esta cidade no universo complexo que nos cerca.

A Introdução apresenta os objetivos, critérios dos cortes cronológicos, seleção das instituições apresentadas, conceito de documento histórico, como o trabalho foi desenvolvido, apresentação em verbetes, sem terminologia ou padrões técnicos-arquivísticos, sendo o conteúdo deles apresentados em quatro partes: dados cadastrais da instituição; histórico; descrição do acervo e indicação de acervos de outra natureza.

O guia propriamente dito vai das páginas 1 a 721 , dividido em: Poder Público: Executivo municipal, Executivo estadual, Legislativo, Judiciário; Cartórios: Cartórios de Registro Civil, Cartório de Notas, Cartórios de Registro de Títulos e Documentos, Cartórios de Protestos de Letras e Títulos, Cartórios de Registro de Imóveis; Cemitérios; Institutos de Pesquisa; Arquivos, Bibliotecas e Centros de Memória; Museus; Instituições Educacionais: Escolas Públicas, Escolas Privadas, Outras Escolas, Ensino Superior; Instituições Religiosas: Adventistas, Afro-Brasileiras, Anglicanas, Batistas, Budistas, Católicas, Espíritas, Evangélicas cristãs, Judaicas, Luteranas, Metodistas, Muçulmanas, Ortodoxas, Presbiterianas, Outras religiões; Associações; Sindicatos e Associações de Classe: Sindicatos de trabalhadores, Sindicatos patronais, Associações de classe; Clubes e Escolas de Samba: Clubes, Escolas de samba; Hospitais e Centros de Saúde, Imprensa e Empresas.

No Anexo, páginas 723 a 753, estão arroladas as instituições que foram contatadas durante o levantamento, mas que não apresentaram respostas ao questionário sobre seus acervos documentais no período previsto.

A edição deste guia preenche a lacuna conhecida sobre a localização de acervos documentais textuais (e também os de outra natureza), constante queixa dos pesquisadores especializados na cidade de São Paulo, seu espaço, seus moradores, as condições de vida, trabalho, educação, saúde, lazer etc.

Este trabalho é uma contribuição muito importante para a pesquisa sobre a cidade, que pela própria ousadia e relevância, destaca os senões que possui e que podem ser corrigidos em uma próxima edição. Reclamamos não apenas do uso da quantidade de páginas para indicar o volume documental guardado, pacotes, ou pastas; da não sistematização da indicação de publicações realizadas/ou das existentes, visto que como aparecem em alguns verbetes, sua não apresentação sugere aos leitores que quando não constam são inexistentes, o que nem sempre corresponde à realidade. Também o critério de separar centros de documentação da instituição matriz pode ser questionada, pois eles não possuem existência autônoma, e seu desmembramento não permite a visualização da instituição maior. A seleção dos cortes cronológicos é uma questão mais séria. A explicação apresentada não corresponde a fatos documentais textuais: a data inicial - 1554, não é a dos primeiros documentos produzidos em São Paulo (como sabem os pesquisadores que realizaram o trabalho de levantamento dos acervos) e a final -1954, alegadamente baseada nos 50 anos de restrição de acesso pleno aos documentos públicos não corresponde nem as instituições nem a documentação. Datar da Fundação ao Quarto Centenário fica como concessão ao conhecimento vulgarizado e consensual sobre a história da cidade, imaginário ideologicamente explorado para a criação de uma identidade paulistana, não uma seleção criteriosa de pesquisadores.

Outro problema é a junção de instâncias diversas no mesmo item, por exemplo, no Legislativo estão os dois, o estadual e o municipal, e, no Judiciário, estão 
as duas, federal (com a relação incompleta) e a estadual. Também no levantamento de institutos de pesquisa o perfil apresentado nem sempre retrata as atividades exercidas e a importância do acervo existente, como no caso da Fundação SEADE, fundamental para as questões de condições de vida, moradia, trabalho, saúde, educação etc., pelas pesquisas sistemáticas que conduz, como as de condição de vida e as de emprego (PCV e PED). Afinal, se o conceito de documentação utilizado é o abrangente, como esquecer de indicar onde localizar os dados econômicos e demográficos de São Paulo, antigos e recentes, e a função de Banco de Dados do governo do Estado? Para não falarmos das publicações, todas muito significativas para a compreensão das transformações da e na sociedade paulistana e paulista.

Contudo, estas observações aleatórias não desmerecem a importância e significação do trabalho, que é importante e contribuição significativa para o desenvolvimento dos estudos sobre a cidade de São Paulo.

O Catálogo de teses e dissertações, 1942-1997 (FFLCH/COMISSÃO DE PÓS-GRADUAÇÃO, 1998) foi realizado sob a responsabilidade da Profa. Dra. Leonor Lopes Fávero, organizado pelo grupo de trabalho das Profas. Dras. Vera Lucia Amaral Ferlini, Maria das Graças de Souza Nascimento e Ana Maria Marques Camargo Marangoni, com a equipe técnica coordenada por Angélica Resende. No senso estrito não pode ser considerado um instrumento de pesquisa sobre a cidade de São Paulo, mas em sentido amplo sim, visto que a Faculdade de Filosofia, Letras e Ciências Humanas está na cidade e que parte ponderável de sua produção tem a cidade e os fenômenos que nela ocorrem como objetos de pesquisa. Geralmente as relações de dissertações de mestrado e teses de doutorado tem sido editadas pelas associações científicas, anualmente, como a ASSOCIAÇÃO BRASILEIRA DE ANTROPOLOGIA/ABA e a ASSOCIAÇÃO NACIONAL DOS PROGRAMAS DE PÓS-GRADUAÇÃO EM EDUCAÇÃO/ANPED fa- zem, ou periodicamente, como a ASSOCIAÇÃO NACIONAL DE HISTÓRIA/ANPUH ${ }^{3}$.

Esta edição retoma e complementa todos os outros trabalhos existentes, editados anteriormente, permitindo a apreciação do trabalho científico e acadêmico concretizado, bem como a colaboração para a formação de recursos humanos - 4498 dissertações e teses realizadas na Faculdade nos 55 anos abarcados pela obra. $\mathrm{O}$ formato é de 20 x $25 \mathrm{~cm}$, e contém: Índice Geral; Apresentação; em sequiência alfabética aparecem os departamentos com as áreas de pós-graduação: Antropologia; Ciência Política; Sociologia; Filosofia; Geografia (2 áreas); História (2 áreas); Lingüística; Letras Clássicas e Vernáculas (5 áreas); Letras Modernas (5 áreas); Línguas Orientais (4 áreas); Teoria Literária e Literatura Comparada, incluindo o Museu de Arqueologia e Etnologia/USP com o Programa de Arqueologia. Possui Índice remissivo de autores e orientadores, e contagem de Dissertações de Teses. Cada programa apresenta seus objetivos, linhas de pesquisa, docentes e em ordem cronológica, mestrados e doutorados. Os trabalhos realizados antes da institucionalização do Sistema Nacional de Pós-Graduação/CAPES/MEC, em 1971, foram inseridos no departamento e área pertinente.

A prática de divulgar dissertações e teses nos últimos anos tem sido da FUNDAÇÃO DE AMPARO À PESQUISA DO ESTADO DE SÃO PAULO/ FAPESP, que gravou duas edições em cd-rom da produção das universidades paulistas em todas as especialidades, que estão em todas bibliotecas informatizadas do sistema universitário e de pesquisa, mas como não foram colocados à venda, o conhecimento de sua existência ainda é restrito. A informa-

\footnotetext{
${ }^{3}$ Produção histórica no Brasil: 1985-1994: catálogo de dissertações e teses dos programas e cursos de pós-graduação em História, coord. Maria Helena Rolim Capelato. São Paulo: Dep. História/FFLCH/USP, 1995. 3 v. $1^{\circ}$. v. - USP.
} 
tização, apesar de crescente, não abrange o universo que poderia ser atingido por um livro.

A tendência que se apresenta para o futuro parece ser a de inserção automática nos Bancos de Dados existentes, quer os de associações científicas, quer os institucionais, dificultando o trabalho analítico no futuro para a percepção das especificidades do local de produção, do conjunto produzido, a complexidade do processo e a socialização do conhecimento. As propostas de divulgação via Internet ainda estão em estágio inicial, mas a produção da USP, de 1985 em diante, pode ser localizada através do SIBI no programa "Dedalus".

Também no ano passado foi distribuído um folheto que é auxiliar precioso para pesquisadores, o Guia dos sebos (SECCHIN, 1997). Todos sabemos da fundamental importância de conhecê-los, quer para adquirir as primeiras edições, necessárias para os estudos comparativos, buscar autor e/ou obra pouco conhecidos, que escaparam das bibliotecas, complementar coleções que foram sendo desfalcadas no de-

\section{Bibliografia}

DIVISÃO DE ARQUIVO DO ESTADO DE SÃO PAULO. Arquivo em Imagens, 1 - Série Última Hora. São Paulo: Arquivo do Estado/IMESP, 1997. 176p. ilust.

DIVISÃO DE ARQUIVO DO ESTADO DE SÃO PAULO. Arquivo em Imagens, 2 - Série Última Hora - Futebol. São Paulo: Arquivo do Estado/ IMESP, 1998. 176p. ilust.

DIVISÃO DE ARQUIVO DO ESTADO DE SÃO PAULO. Crimes em São Paulo: catálogo de fundos dos Juízos da Capital existentes no Arquivo do Estado de São Paulo (18211899). São Paulo: Divisão de Arquivo do Estado/IMESP/ FNC-MinC, 1998. 379p.

DIVISÃO DE ARQUIVO DO ESTADO DE SÃO PAULO. Guia do acervo do Arquivo do Estado. São Paulo: Divisão do Arquivo/IMESP, 1997. 85p. $+3 \mathrm{~s} / \mathrm{n}$., ilust.

DIVISÃO DE ARQUIVO DO ESTADO DE SÃO PAULO. Inventário DEOPS: Alemanha, módulo I, org. Maria Luiza Tucci Carneiro. São Paulo: Arquivo do Estado/USP/Instituto Goethe/IMESP, 1997. 165p. ilust. correr dos anos, etc. etc. Sem falar que através deles muitas bibliotecas pessoais foram iniciadas e mantidas. Percorrê-los, conhecê-los é paixão pessoal, atividade sistemática, mas em São Paulo, até mesmo eles mudam de lugar, nome, proprietário - as agendas de endereços vão sendo riscadas, corrigidas, ilegíveis. A edição no formato $14 \times 21 \mathrm{~cm}$. tem o objetivo de suprir a lacuna existente, contendo a relação 44 sebos, identificando local, horário de funcionamento, condições de venda, forma de aquisição de acervos, com um índice telefônico por loja no final (a parte mais desatualizada das informações).

Aguardamos as edições que estão programadas e esperamos que nos próximos anos as atividades de organização e edição de instrumentos de pesquisa continuem merecendo a atenção das instituições, apoio das agências financiadoras, e tenham continuidade, para auxiliar os pesquisadores em suas atividades, fortalecendo a profissionalização dos historiadores e dos arquivistas.

DIVISÃO DE ARQUIVO DO ESTADO DE SÃO PAULO. São Paulo em revista: catálogo de publicações da imprensa cultural e de variedades paulistana, 1870-1930, org. Heloísa Faria Cruz. São Paulo: Divisão do Arquivo do Estado/ IMESP/CEDIC-PUC/SP, 1997. 280p., ilust. (Coleção memória, documentação e pesquisa, 4).

DIVISÃO DE ARQUIVO DO ESTADO DE SÃO PAULO. $M a-$ nual de procedimentos para tratamento documental - Arquivo do Estado de São Paulo. Resultado do projeto piloto "Tratamento técnico do acervo permanente da DAESP", financiado pelo Fundo Nacional de Cultura através da Secretaria de Apoio à Cultura do Ministério da Cultura. São Paulo: Arquivo do Estado/IMESP, 1998. 50p.

DIVISÃO DE ARQUIVO DO ESTADO DE SÃO PAULO. O $s$ voluntários paulistas na Guerra do Paraguai. São Paulo: Divisão de Arquivo/IMESP, 1997. 171p. Ed. fac-similar com mapas, plantas, documentos e transcrições. 
FACULDADE DE FILOSOFIA, LETRAS E CIÊNCIAS HUMANAS/USP - COMISSÃO DE PÓS-GRADUAÇÃO. Catálogo de teses e dissertações, 1942-1997. São Paulo: Comissão de Pós -Graduação/FFLCH/USP, 1998. 423p.

FERNANDES, Paula Porta S. e outros. Guia dos documentos históricos na cidade de São Paulo, 1554/1954. Documentação textual. Coordenação de ... São Paulo: Ed. HUCITEC/NEPS, 1998. 794p. + XXII.

SECCHIN, Antônio Carlos. Guia dos sebos da cidade de São Paulo. Rio de Janeiro: Fundação Biblioteca Nacional/Dep. Nacional do Livro, 1997. 32f.

Endereço da Autora: Depto. de História - FFLCH/USP - Av. Prof. Lineu Prestes, 338 - CEP 05508-900 - Cidade Universitária - SP Brasil - Tel. (0xx) 11- 3818-3701 - Fax (0xx) 11- 210-2314 